\title{
Psychological risk factors of micro- and macrovascular outcomes in primary care patients with type 2 diabetes: rationale and design of the DiaDDZoB Study
}

\author{
Giesje Nefs, François Pouwer*, Johan Denollet, Victor JM Pop
}

\begin{abstract}
Background: Depression is a common psychiatric complication of diabetes, but little is known about the natural course and the consequences of depressive symptoms in primary care patients with type 2 diabetes. While depression has been related to poor glycemic control and increased risk for macrovascular disease, its association with microvascular complications remains understudied. The predictive role of other psychological risk factors such as Type D (distressed) personality and the mechanisms that possibly link depression and Type D personality with poor vascular outcomes are also still unclear.

Methods/Design: This prospective cohort study will examine: (1) the course of depressive symptoms in primary care patients with type 2 diabetes; (2) whether depressive symptoms and Type D personality are associated with the development of microvascular and/or macrovascular complications and with the risk of all-cause or vascular mortality; and (3) the behavioral and physiological mechanisms that may mediate these associations. The DiaDDZoB Study is embedded within the larger DIAZOB Primary Care Diabetes study, which covers a comprehensive cohort of type 2 diabetes patients treated by over 200 primary care physicians in South-East Brabant, The Netherlands. These patients will be followed during their lifetime and are assessed annually for demographic, clinical, lifestyle and psychosocial factors. Measurements include an interviewer-administered and self-report questionnaire, regular care laboratory tests and physical examinations, and pharmacy medication records. The DiaDDZoB Study uses data that have been collected during the original baseline assessment in 2005 $\left(M_{0} ; N=2,460\right)$ and the $2007\left(M_{1} ; N=2,225\right)$ and $2008\left(M_{2} ; N=2,032\right)$ follow-up assessments.

Discussion: The DiaDDZoB Study is expected to contribute to the current understanding of the course of depression in primary care patients with type 2 diabetes and will also test whether depressed patients or those with Type D personality are at increased risk for (further) development of micro- and cardiovascular disease. More knowledge about the mechanisms behind this association is needed to guide new intervention studies.
\end{abstract}

\section{Background}

The number of people with diabetes mellitus is increasing rapidly worldwide. Based on aging and other demographic changes, prevalence estimates of this chronic metabolic disease are projected to rise from 171 million in 2000 to 366 million in 2030 [1]. As the disease progresses, diabetes patients are often confronted with

\footnotetext{
* Correspondence: f.pouwer@uvt.nl

CoRPS - Center of Research on Psychology in Somatic diseases, Department of Medical Psychology and Neuropsychology, Tilburg University, Tilburg, The Netherlands
}

(c) 2010 Nefs et al; licensee BioMed Central Ltd. This is an Open Access article distributed under the terms of the Creative Commons Attribution License (http://creativecommons.org/licenses/by/2.0), which permits unrestricted use, distribution, and reproduction in any medium, provided the original work is properly cited. long-term vascular complications. While premature carstroke and peripheral arterial disease) accounts for considerable morbidity and mortality, complications of microvascular origin also contribute significantly to adverse health outcomes [2]. To date, diabetes remains a predominant cause of vision loss, renal failure and lower extremity amputations in developed countries [3]. A large-scaled study among over 7,000 patients with type 2 diabetes in eight European countries concluded that approximately $72 \%$ of the participants had at least 
one complication, while $24 \%$ of the total study group had both micro- and macrovascular complications [4]. Not surprisingly, the presence of these vascular conditions has a substantial negative impact on both overall healthcare expenditures [4] and patients' quality of life [5].

\section{Depression is common in type 2 diabetes}

Depression is another common and burdensome complication of type 2 diabetes. A recent meta-analysis of ten controlled studies showed that the prevalence of depression was significantly higher in patients with type 2 diabetes compared with non-diabetic controls (18 vs. $10 \%$, OR $=1.6,95 \%$ CI 1.2-2.0) [6]. Even though depression is a common co-morbidity in diabetes, little longitudinal research has been undertaken with respect to its natural course in type 2 diabetes [7]. A meta-analysis of seven prospective studies by Mezuk et al., all excluding prevalent cases of depression at baseline, concluded that the association between type 2 diabetes and the incidence of depression is only modest $(\mathrm{RR}=1.15,95 \% \mathrm{CI}$ 1.02 - 1.30) [8]. However, a negative depression screening score at study entry cannot rule out a history of depression and therefore the conclusion by Mezuk et al., about the role of diabetes as a risk factor for "new" cases of depression, might be premature [9]. Two meta-analyses showed that the reversed association, with depression as a risk factor for the onset of type 2 diabetes, is stronger. Depressed adults have a $30-60 \%$ increased risk of developing type 2 diabetes $[8,10]$.

There is abundant evidence showing that depression can be regarded as a chronic condition for many patients, with periods of (partial) remission and relapse in community [11] and primary care [12] samples. Although the existing literature suggests that depression is even more persistent in diabetes patients, these studies are hampered by relatively small numbers of type 2 diabetes patients $[7,13]$, the inclusion of selected populations from specialised clinics [14] and the measurement of depression in a selected sample of patients who have participated in an antidepressant drug trial [13] or diabetes education programme $[7,15]$. A large study examining different aspects of the natural course (incidence, remission, recurrence) of depression in a representative sample of primary care patients with type 2 diabetes is currently lacking.

\section{Depression is associated with poor disease outcomes}

Depression in diabetes was found to be associated with poor glycemic control [16], a higher number of cardiovascular risk factors [17], micro- and macrovascular complications [18], and an increased mortality risk [19-22]. Meta-analyses of prospective studies suggest that depression is associated with the onset or progression of cardiovascular disease in primary care and community samples [23] and post-myocardial infarction patients [24]. An important limitation of the current diabetes literature is that most studies on the association between depression and vascular conditions used cross-sectional data [18], hence precluding any inferences about possible causal pathways. In recent years, a limited number of prospective studies have been published. While depression predicted the incidence of vascular complications $[19,25]$ and greater all-cause mortality [19-22], its effect on mortality due to vascular causes still is unclear $[20,26]$. So far, the emphasis in these studies has been on macrovascular outcomes, in particular coronary heart disease. Only two large longitudinal studies have considered the association between depression and the incidence of microvascular conditions. One of these was conducted in a sample of elderly Mexican-Americans and used self-report to ascertain the presence of complications [19], while the other only examined advanced complications, including end-stage renal disease, low vision or blindness, and amputations [27].

\section{Type D personality and cardiovascular disease}

Most research on the psychological aspects of diabetes has focused on depression, leaving the role of other dimensions of emotional distress, such as anxiety and more stable emotional traits, as understudied areas. An emerging risk factor in the cardiovascular research domain is "Type D (distressed) personality", which is defined by the two stable personality traits "negative affectivity" and "social inhibition" [28]. Individuals with this personality type tend to experience negative emotions across time and situations, but are inclined to inhibit the expression of emotions and behaviors in order to avoid disapproval or rejection $[28,29]$. Type D personality is relatively common, with prevalence estimates ranging from $21 \%$ in the general population to $28 \%$ in coronary heart disease patients and $53 \%$ in hypertensives [28]. Accumulating evidence suggests that having a Type $\mathrm{D}$ personality is associated with a 2 to 5 -fold increased risk of adverse prognosis, impaired quality of life and emotional distress across cardiovascular patient groups, independent of standard biomedical risk factors [29,30]. No studies to date have been undertaken to examine the impact of Type D personality on disease-related outcomes in patients with type 2 diabetes, although vascular disease is relatively common in this group.

\section{Mechanisms that could link depression and Type D with poor outcomes}

Several plausible mechanisms have been hypothesized to mediate the association between emotional distress (depression, Type D) and poor vascular outcomes. 
Potential mediators include health behaviors, such as smoking, alcohol consumption and physical inactivity, and biomedical factors (e.g. underlying cardiac disease severity, an unfavorable cardiovascular risk profile/the "metabolic syndrome", immune processes) [31-33]. In the Heart and Soul Study, a cohort of more than 1,000 outpatients with stable coronary heart disease, the association between depressive symptoms and adverse cardiovascular events was largely explained by behavioral factors, in particular physical inactivity (32\% change in effect size) [33]. The extent to which these mechanisms account for the increased risk of vascular complications in distressed diabetes patients, should this association exist, is still unclear.

\section{Innovative aspects of the DiaDDZoB Study}

To summarize: (1) While there are numerous studies that aimed to determine the prevalence of depression in type 2 diabetes patients, little is known about the natural course of depression in diabetes (incidence, recurrence, remission). (2) The majority of studies examining the association between emotional distress and vascular disease had a cross-sectional design, focused on depression and had macrovascular disease as outcome. The role of other aspects of emotional distress and the association with common microvascular complications is therefore still unclear. (3) It is unknown which behavioral and/or biomedical mechanisms may account for the hypothesized associations between emotional distress and vascular conditions. The DiaDDZoB Study (Diabetes, Depression, Type D Personality ZuidoostBrabant) will examine the abovementioned issues in a cohort of primary care patients with type 2 diabetes.

\section{Methods/Design}

\section{Aims and hypotheses}

The DiaDDZoB Study was designed as a prospective cohort study and aims to address the following main research questions:

1. What is the natural course (prevalence, incidence, recurrence, remission) of depressive symptoms in a sample of primary care patients with type 2 diabetes?

2 . Do patients with type 2 diabetes and co-morbid emotional distress (as evidenced by an increased level of depressive symptoms and/or Type D personality) have an increased risk for the onset/progression of microand macrovascular complications?

3. Do these types of emotional distress also increase the risk of all-cause or vascular mortality?

4. When a significant relation is found in (2) or (3): which factors mediate the association between emotional distress and diabetes outcomes?

Based on the current literature, we hypothesize the following: Approximately one fifth of our sample will have an increased level of depressive symptoms at each separate measurement occasion (prevalence). In the group of patients without a self-reported history of depression, incident depression will be low $(<5 \%)$. In the patients with a history of depression, recurrence rates will be relatively high (at least 25\%). Significant risk factors for depression most likely will be: (1) psychosocial factors such as stressful life events and loneliness and (2) the presence (onset or progression) of vascular complications. We also hypothesize that patients with co-morbid distress (either depressive symptoms or Type D) will be at increased risk for the development of micro- and macrovascular conditions and both all-cause and vascular mortality; these associations are (partly) explained by behavioral (smoking behavior, alcohol consumption, physical inactivity) and biomedical (cardiovascular disease history, characteristics of the metabolic syndrome) mechanisms.

\section{Study design}

From 2005 onwards, data for the DiaDDZoB Study have been collected within the framework of the DIAZOB (Diabetes care Zuidoost-Brabant) project, a large-scale diabetes management programme for primary care patients with type 2 diabetes. To evaluate the implementation of this standard diabetes care programme in daily practice, an observational cohort study (the DIAZOB Primary Care Diabetes study) was designed, including annual assessments of a broad range of demographic, medical, lifestyle and psychosocial factors [34,35]. Follow-up surveys of the total DIAZOB population $(\mathrm{N} \approx$ $12,000)$ are planned for the upcoming years. The DiaDDZoB Study builds upon data from three completed measurement occasions. The original baseline measurement $\left(\mathrm{M}_{0}\right)$ took place in the second half of 2005. Follow-up assessments were realized in $2007\left(\mathrm{M}_{1}\right)$ and $2008\left(\mathrm{M}_{2}\right)$

\section{Subjects}

The ongoing assessment of the DIAZOB-cohort is conducted in collaboration with over 200 general practitioners who are currently allied to PoZoB (Praktijkondersteuning Zuidoost Brabant), a large managed care organisation responsible for the implementation of the DIAZOB standard care programme. The practices are located in the South-Eastern area of the Netherlands, mainly in the region south of the city of Eindhoven. The patient population is residing in rural and suburban areas. To be included in the DIAZOB Primary Care Diabetes study, the patient had to be formally diagnosed with type 2 diabetes according to the guidelines of the Dutch College of General Practitioners (as evidenced by either a fasting glucose concentration of $>6.9 \mathrm{mmol} / \mathrm{l}$ in venous plasma or $>6.0 \mathrm{mmol} / \mathrm{l}$ in capillary blood on 
two separate days or an arbitrary glucose level $>11.0$ $\mathrm{mmol} / \mathrm{l}$ in the presence of the classic hyperglycemia symptoms [36]. These criteria are comparable to the recommendations of the American Diabetes Association [37]. Other inclusion criteria were: the patient was receiving treatment for diabetes in the DIAZOB diabetes care programme, had the primary care practice nurse as his/her main health care provider for diabetes issues, was at least 18 years old (with no upper age limit) and had sufficient mastery of the Dutch language. Patients were excluded if they had a treatment or condition other than type 2 diabetes as the primary cause of the hyperglycemia and/or were physically/mentally incapable of completing a questionnaire (e.g. co-morbid dementia, terminal cancer), as judged by the primary care practice nurse.

\section{Recruitment of patients}

From 2005 onward, patients were invited by their primary care practice nurse to participate in the DIAZOB standard care project. In the period of April (pilot) and June - December 2005, the DIAZOB patients were informed of the evaluation study and received a detailed description of its practical and scientific aim. Patients who were willing to participate were asked to sign an informed consent form. Consent was sought for (a) using the anonymised data (questionnaire and medical information) for reports and scientific publications; requesting information from the patient's (b) pharmacist and (c) specialist; and (d) informing the general practitioner or primary care practice nurse of study results, if necessary.

\section{Participant drop-out}

In the beginning of 2005, the total number of type 2 diabetes patients in the area covered by the participating general practitioners at that time was estimated at 3,000 to 3,500. During the baseline inclusion period, 3,017 patients were considered for participation in the study. A detailed overview of the study's participation and drop-out rate can be found in Figure 1. Reasons for baseline non-response could be grouped into "patient characteristics" (e.g. not meeting inclusion criteria/screening positive on exclusion criteria, refusing to participate, not showing up at the baseline interview) and "practice nurse characteristics" (lack of time, omitting to invite newly diagnosed or insulin-using patients). Of the resulting 2,460 patients, 2,448 (99.5\%) attended the interview and 1,850 (75.2\%) returned the self-report questionnaire that had to be filled in at home. For the $M_{1}$ and $M_{2}$ assessments, 2,225 and 2,032 patients were available, respectively.

\section{Measures used in the DiaDDZoB Study}

The DIAZOB Primary Care Diabetes study measurements include an interviewer-administered and self-report questionnaire, results from regular care laboratory tests and physical examinations, and pharmacy medication records. An overview of the variables that were used for the DiaDDZoB Study can be found in Table 1.

\section{Data acquired during an interview with the primary care practice nurse}

The interview-administered questionnaire was filled out by the practice nurse along with the patient during regular diabetes check-up and included questions about demographic factors, clinical parameters, hyperglycemia treatment and health behaviors.

Demographics Information was gathered about age, gender and ethnicity.

Clinical parameters At baseline, the primary care practice nurse recorded the number of months/years since diabetes diagnosis and took a basic medical history, including self-reported history of depression. Selfreported medical diagnoses were verified through inspection of the medical record. At follow-up, onset and/or progression of vascular complications and other conditions was recorded, as was mortality date and cause of death for those patients who deceased during the study.

Hyperglycemia treatment At each measurement occasion, the practice nurse documented whether patients were currently treated for their hyperglycemia by diet, oral agents, insulin or a combination of these treatment modalities.

Health behaviors/Lifestyle A basic overview of current and former smoking behavior and alcohol consumption was collected at the baseline assessment. Changes to this baseline pattern were recorded during follow-up. Physical activity was assessed by means of two items. Patients had to indicate how many hours per week they spent on (a) "active" (all physical activities other than practicing sports, e.g. gardening, walking, cycling, climbing stairs) and (b) "sportive" physical activities (e.g. sports, fitness).

\section{Data acquired using self-report questionnaires}

A second questionnaire was completed by the patient at home and addressed several additional demographic variables and psychosocial factors. For practical purposes, the questions about health behaviors were transferred from the interview-administered to the self-report questionnaire for the follow-up measurements.

Demographics The demographic measures included marital status (dichotomized as being single versus having a partner), living situation (independent versus dependent of others), employment status (paid employment versus no paid employment/unemployed/disabled/ retired) and educational level (low education versus middle/high education).

Depressive symptoms Depressive symptoms during the last seven days were assessed using a validated Dutch 


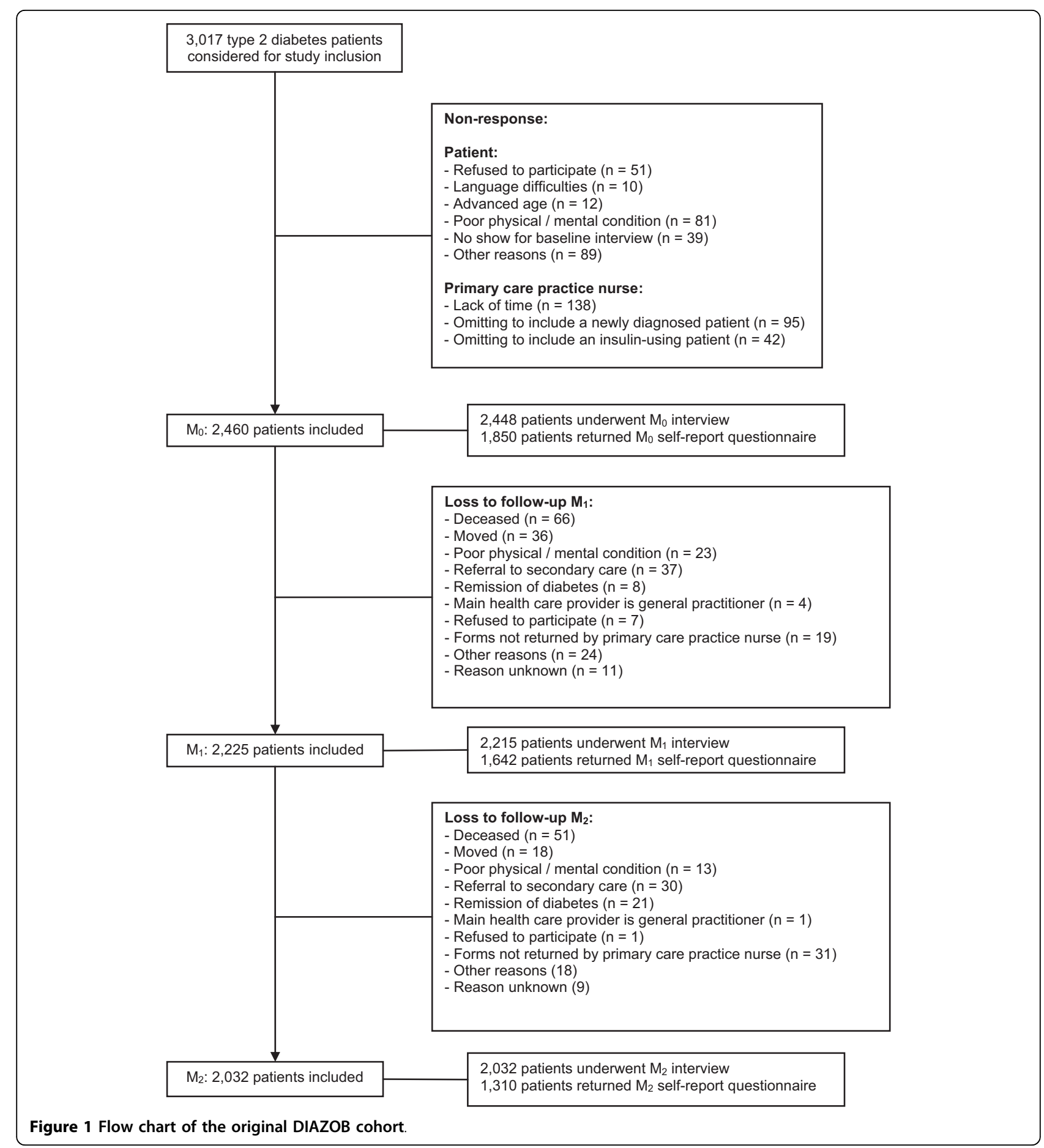

version of the Edinburgh Depression Scale (EDS) [38]. This is a 10-item self-rating scale in which each item is scored on a four-point scale. Total scores range from 0 to 30 points. The EDS was originally developed to measure post partum depression [39], but has later been validated in non-postnatal women [40], women around menopausal age [41], men [42] and community samples
[43]. Although cut-off points for predicting a diagnosis of clinical depression vary [44], a cut-off score of 12 or more seems to have satisfactory sensitivity and specificity $[41,43]$.

Type D personality Type D personality was assessed using the Type D Scale-14 [28]. This questionnaire consists of 14 items, which are scored on a five-point rating 
Table 1 Measurements included in the DiaDDZoB Study

\begin{tabular}{|c|c|c|}
\hline Variable & Categories & Measurement occasion \\
\hline \multicolumn{3}{|l|}{ Demographic factors } \\
\hline Age & & $M_{0}$ \\
\hline Gender & Male, female & $M_{0}$ \\
\hline Ethnicity & $\begin{array}{l}\text { Dutch, other Caucasian (white Western) groups, } \\
\text { other (Asian, black, Turkish/Moroccan) }\end{array}$ & $M_{0}$ \\
\hline Marital status & $\begin{array}{l}\text { Married/living together, single, LAT relationship, divorced/ } \\
\text { separated, widowed }\end{array}$ & $M_{0}, M_{1}, M_{2}$ \\
\hline Living situation & $\begin{array}{l}\text { Independent, residing with family/friends, residing in } \\
\text { a nursing home }\end{array}$ & $M_{0}, M_{1}, M_{2}$ \\
\hline Employment status & $\begin{array}{l}\text { Paid employment, unemployment, disabled, no paid } \\
\text { employment, retired }\end{array}$ & $M_{0}, M_{1}, M_{2}$ \\
\hline Education level & $\begin{array}{l}\text { Primary school, primary vocational education, secondary } \\
\text { school, secondary vocational education, higher vocational } \\
\text { education, university }\end{array}$ & $M_{0}$ \\
\hline \multicolumn{3}{|l|}{ Medical history } \\
\hline Disease duration & Months/years since diabetes diagnosis & $M_{0}, M_{1}$ \\
\hline Medical history & $\begin{array}{l}\mathrm{M}_{0} \text { : lifetime history: } \\
\text { arterial disease, bypass/angioplasty, myocardial } \\
\text { infarction, stroke, angina pectoris, high cholesterol, kidney } \\
\text { disease, asthma/COPD, cancer, } \\
\text { rheumatic disorder, depression, burn-out } \\
\mathrm{M}_{1} \text { and } \mathrm{M}_{2} \text { : during last } 12 \text { months: } \\
\text { arterial disease, bypass/angioplasty, myocardial } \\
\text { infarction, stroke, angina pectoris, high cholesterol, } \\
\text { asthma/COPD, osteoporosis, depression, kidney disease }\end{array}$ & $M_{0}, M_{1}, M_{2}$ \\
\hline \multicolumn{3}{|l|}{ Treatment } \\
\hline Current hyperglycemia treatment modality & $\begin{array}{l}\text { None, diet, diet/oral agents, diet/ } \\
\text { insulin, diet/oral agents/insulin, other }\end{array}$ & $M_{0}, M_{1}, M_{2}$ \\
\hline Medication use & $\begin{array}{l}\text { ACE inhibitors, } \beta \text {-blockers, calcium } \\
\text { antagonists, diuretics, other } \\
\text { antihypertensive agents, statins }\end{array}$ & $M_{0}, M_{1}, M_{2}$ \\
\hline \multicolumn{3}{|l|}{ Laboratory tests } \\
\hline $\mathrm{HbA}_{1 \mathrm{c}}$ & & $M_{0}, M_{1}, M_{2}$ \\
\hline Fasting glucose & & $M_{0}, M_{1}, M_{2}$ \\
\hline \multirow[t]{4}{*}{ Cholesterol } & Total cholesterol & $M_{0}, M_{1}, M_{2}$ \\
\hline & LDL-cholesterol & $M_{0}, M_{1}, M_{2}$ \\
\hline & HDL-cholesterol & $M_{0}, M_{1}, M_{2}$ \\
\hline & Triglycerides & $M_{0}, M_{1}, M_{2}$ \\
\hline \multirow[t]{4}{*}{ Protein levels } & Albumin & $M_{0}, M_{1}, M_{2}$ \\
\hline & Creatinin & $M_{0}, M_{1}, M_{2}$ \\
\hline & Albumin-to-creatinin ratio & $M_{0}, M_{1}, M_{2}$ \\
\hline & MDRD clearance & $M_{1}, M_{2}$ \\
\hline \multicolumn{3}{|l|}{ Physical examination } \\
\hline Length & Length in metres & $M_{0}, M_{1}, M_{2}$ \\
\hline Weight & Weight in kilograms & $M_{0}, M_{1}, M_{2}$ \\
\hline Body Mass Index (BMI) & Weight in kilograms/(length in metres) ${ }^{2}$ & \\
\hline \multirow[t]{2}{*}{ Blood pressure } & Systolic & $M_{0}, M_{1}, M_{2}$ \\
\hline & Diastolic & $M_{0}, M_{1}, M_{2}$ \\
\hline Fundus photography & Unassessable, normal, retinopathy & $M_{0}, M_{1}, M_{2}$ \\
\hline Foot examination & $\begin{array}{l}M_{0} \text { : Normal, abnormal } \\
M_{1} \text { and } M_{2} \text { : Normal, neuropathy, ischemia, wound/ulcer, } \\
\text { excessive coldness }\end{array}$ & $M_{0}, M_{1}, M_{2}$ \\
\hline \multicolumn{3}{|l|}{ Lifestyle indicators } \\
\hline Smoking behavior & $\begin{array}{l}\text { Current smoking: yes/no, number of cigarettes per day } \\
\text { Additional for } M_{0} \text { : smoking history }\end{array}$ & $M_{0}, M_{1}, M_{2}$ \\
\hline
\end{tabular}


Table 1: Measurements included in the DiaDDZoB Study (Continued)

\begin{tabular}{lll}
\hline \multicolumn{1}{c|}{ Alcohol consumption } & $\begin{array}{l}\text { Current alcohol consumption: yes/no, number of } \\
\text { consumptions per week } \\
\text { Additional for } M_{0} \text { : history of alcohol consumption }\end{array}$ & $M_{0}, M_{1}, M_{2}$ \\
Physical activity & Hours per week of active physical activity & $M_{0}, M_{1}, M_{2}$ \\
& Hours per week of sportive physical activity & $M_{0}, M_{1}, M_{2}$ \\
Psychological factors & & $M_{0}, M_{1}, M_{2}$ \\
Depressive symptoms & Edinburgh Depression Scale (EDS) & $M_{1}, M_{2}$ \\
Type D personality & Type D Scale-14 (DS14) & $M_{0}, M_{1}, M_{2}$ \\
Social support & O'Hara's modified Social Support Scale & $M_{0}, M_{1}, M_{2}$ \\
Loneliness & Single item concerning feelings of loneliness in & $M_{0}, M_{1}, M_{2}$ \\
Stressful life events & the past 12 months & Single item concerning stressful life event(s) in \\
& the past 12 months & \\
\hline
\end{tabular}

scale ranging from $0=$ "false" to $4=$ "true". The DS14 comprises two scales, one measuring level of negative affectivity (NA) and the other social inhibition (SI). Subjects who obtain a score of ten or more on both scales are considered to have a Type D personality [28]. Both scales have been shown to be internally consistent (Cronbach's $\alpha=0.88$ for the NA scale and 0.86 for the SI scale), stable over an 18-month period [45] and are independent of mood and health status $[28,45]$.

Other psychosocial factors Social support was measured using O'Hara's modified Social Support Scale [46], comprising three items. Answer categories range from 0 to 4 points, with 0 indicating "no social support at all" and 4 indicating "extensive social support". The total social support score is obtained by adding scores on all three items. A single item was used to measure feelings of loneliness in the past 12 months, which were scored on a scale from 1 to 10 points, with a score of 1 meaning "I never felt lonely" and a score of 10, "I always felt lonely". To account for non-diabetes related stressors, respondents were asked if they had experienced a stressful life event in the previous 12 months (e.g. loss of a loved one, a break-in, relationship problems, loss of work, serious financial problems, physical/mental abuse).

\section{Laboratory tests and physical examinations}

Biomedical parameters were derived from standard care laboratory tests and physical examinations carried out by the Diagnostic Centre Eindhoven, a primary care institution where biological records of the regional diabetes population are filed after each regular care checkup appointment. For the DIAZOB project, blood was drawn annually to determine glycemic control (glycosylated hemoglobin or $\mathrm{HbA}_{1 \mathrm{C}}$ levels, fasting glucose), creatinin, the MDRD clearance (only at follow-up) and cholesterol values (total, LDL, HDL, triglycerides); urine samples were taken to assess albumin and the albuminto-creatinin ratio. As for the physical examination, blood pressure measurements (systolic and diastolic), body mass index (BMI; weight in kilograms/length in metres ${ }^{2}$ ), and fundus photography and foot screening results were provided. To diagnose retinopathy, digital fundus photography was carried out by a biometrist and interpreted by an ophthalmologist. Foot screening included a neurological and vascular examination (Doppler test), and inspection of feet and shoes by a podotherapist or a biometrist under supervision. For the baseline measurement, only the presence of abnormalities to the feet was recorded. During follow-up testing, the lower extremities were assessed for neuropathy, ischemia, wounds/ulcers and excessive coldness.

\section{Pharmacy medication records}

With the patient's consent, information regarding prescribed medication was obtained from local pharmacists. In addition to the medication applied for the management of hyperglycemia, the use of cardiovascular agents (including several antihypertensives and a class of cholesterol-lowering drugs) was registered.

\section{Ethical principles}

This study was planned and conducted in accordance with the medical professional codex and the Helsinki Declaration of 1996 [47]. Written informed consent was obtained from all participants. The study protocol of the DiaDDZoB Study was approved by the medical research ethics committee of a local hospital, the Máxima Medical Centre in Veldhoven (NL27239.015.09).

\section{Planned statistic analyses}

Statistical analyses will be performed using the latest version of the Statistical Package for Social Sciences (SPSS). A p $<0.05$ significance level will be adopted in all statistical tests. As the number of previous studies on these research topics is limited, we choose to use twosided tests in all analyses.

Frequencies will be provided for (1) the prevalence, (2) incidence (with/without self-reported history of 
depression), (3) recurrence (high score across two or three assessments) and (4) other patterns of relapse and remission of high depressive symptoms (EDS-score of 12 or more). In addition, logistic regression analyses will be used to determine significant predictors of these different course patterns. Baseline characteristics of patients with/without high depressive symptoms (EDSscore of 12 or more) and with/without a Type D personality will be compared using independent-samples $\mathrm{t}$-tests and $\mathrm{X}^{2}$ tests. To evaluate the vascular risk associated with increased levels of emotional distress, we will perform logistic regression analyses for (1) the development of each separate micro- and macrovascular complication and (2) a composite measure of vascular disease (the development of any vascular condition) during the two year follow-up period, with either depression or Type D personality as the independent variable. The group of participants with low depressive symptoms or no Type D personality, respectively, will be used as the reference category. Analogous analyses will be used for mortality, with the dependent variable defined as (1) all-cause mortality or (2) (cardio)vascular mortality, as registered in primary care medical records up until December 2008. Before proceeding to the multivariate statistics, several study variables will be evaluated for their potential as confounders or mediators in the association between emotional distress and disease outcomes (the onset/progression of micro- and macrovascular complications, all-cause and vascular mortality). In line with the methods used in a study by Whooley et al. [33], we will adopt a $>5 \%$ change in the effect size (odds ratio) for emotional distress before and after adjustment for the variable in question as the criterion to identify suitable mediating or confounding factors. All variables satisfying these conditions will be included in the final logistic regression models. In addition, we will look at mediating variables more closely using one of the statistical methods described in the recent article by MacKinnon, Fairchild and Fritz [48].

\section{Power calculation}

The sample size was determined using PASS 2008 [49] and was based on the logistic regression analyses for the main research question ("Do patients with type 2 diabetes and co-morbid emotional distress have an increased risk for the onset/progression of micro- and macrovascular complications?"). Assuming a power of 0.80 , an alpha level of 0.05 , two-sided testing, and a baseline prevalence rate of $20 \%$ for the binary independent variable (either high levels of depressive symptoms or Type D personality), we calculated the sample size for a range of scenarios. Based on earlier primary care and community studies $[19,27]$ and on known characteristics of the DIAZOB population, we expect a two-year cumulative event rate (the development of any vascular complication) of $10-15 \%$. In psychological research, $\mathrm{R}^{2}$ (achieved when emotional distress is regressed on the other independent variables) usually ranges from 0.20 0.30 . Assuming equivalence between $\mathrm{OR} / \mathrm{RR} / \mathrm{HR}$ due to the relatively low event rate of vascular outcomes, the majority of earlier studies on the risk of vascular disease in diabetes patients, primary care/community samples and post-myocardial infarction patients has found an effect size for depression of approximately $1.5-2.0$ $[23,24,27]$. Therefore, the entered values were either $0.10,0.125$ or 0.15 for $\mathrm{P}_{0}$ (the probability that a participant develops any vascular complication during the two year follow-up period, given that he/she has a low level of depressive symptoms or no Type D personality at baseline), $0.20,0.25$ or 0.30 for $\mathrm{R}^{2}$, and $1.5,1.75$ or 2.0 for the OR. Sample sizes ranged from 3905 in the most conservative scenario $\left(\mathrm{P}_{0}=10, \mathrm{R}^{2}=0.30\right.$ and $\left.\mathrm{OR}=1.5\right)$ to 764 in the least restricted scenario $\left(P_{0}=15, R^{2}=\right.$ 0.20 and $\mathrm{OR}=2.0)$. When positing a middle-ground scenario $\left(P_{0}=0.125 ; R^{2}=0.25\right.$ and $\left.O R=1.75\right)$, the study needs a total of 1499 participants to detect an OR of 1.75 . Anticipating an annual $10 \%$ loss to follow-up (death, serious illness, moving), we need to include approximately 1850 patients at baseline. As we expect a $40 \%$ non-response/exclusion rate, we will consider for eligibility the total patient group $(\mathrm{n} \approx 3000)$.

\section{Discussion}

As the prevalence of type 2 diabetes is high and the absolute numbers of patients with both diabetes and depression will continue to rise considerably in the next decades, it has become even more essential to further increase our understanding of the associations between diabetes and depression. Currently, our knowledge about this area is still limited. The present paper gives an outline of the theoretical background and methodology of the DiaDDZoB Study, a Dutch prospective cohort study in primary diabetes care, which aims to answer several key research questions regarding the course and vascular impact of depression and Type D personality in patients with type 2 diabetes.

The major strengths of the DiaDDZoB Study include its longitudinal design and relatively large sample size, its focus on type 2 diabetes patients who are being treated in a primary care setting, the wealth of detailed patient information that is available, and the policy to verify self-reported disease by inspection of medical records. The results of this study may lead to the identification of high risk patients and could guide the development of future intervention studies.

While the DIAZOB Primary Care Diabetes study aims to include a relatively unselected patient population, depressive symptoms (including a depressed mood or 
markedly diminished interest, loss of energy and a diminished ability to think or concentrate) could have negatively affected the initial decision to participate in those patients who would otherwise have screened positive for depression on the EDS. In a similar vein, as the nurse-led interview required a certain amount of openness and direct communication with a health provider about disease and concurrent complaints, social inhibition might have deterred patients with a Type D personality. In a study of 178 patients with chronic heart failure, patients with a Type D personality not only experienced and worried more about cardiac symptoms, they also were less likely to report these symptoms to their cardiologist or nurse [50].

The sharp rise in the number of patients with type 2 diabetes has resulted in a gradual shift from secondary to primary care, thereby placing considerable demands on primary health care teams [51]. Secondary care consultations or referrals are indicated in case of more complex disease management, e.g. in the presence of complications or poorly regulated blood glucose levels $[52,53]$. Seeing that approximately $3 \%(67 / 2,460)$ of all patients participating in the baseline assessment dropped out of the study after a secondary care referral, future assessments should be planned and carried out in close cooperation with hospital practitioners to keep the cohort intact. To alleviate some of the workload for general practitioners, the primary care nurse specialist has been introduced as the main care-provider for patients with type 2 diabetes in family practice [54]. Since nurse practitioners generally provide longer consultations and are trained to focus on the medical, practical as well as the emotional aspects of diabetes [55], depression prevalence estimates could have been lowered with more adequate detection and subsequent treatment of depression. Unfortunately, earlier work has shown that the reverse is probably true, i.e. the presence of emotional problems was recorded in the medical chart in only $20-30 \%$ of diabetes patients with high scores on questionnaires measuring emotional distress [55].

Although a recent cohort study has investigated whether depression runs a chronic course with high rates of recurrence in primary care [12], there is a paucity of research on the trajectory of emotional distress in specific chronic diseases. While our annual screening method most likely will identify a subsample with recurrent, high levels of depressive symptoms, a prospective design with yearly follow-up assessments will by definition miss some patients with a relapsing-remitting symptom profile who happen to be in complete or partial remission at the assessment occasion. While an indepth characterization of short-term fluctuations in emotional distress goes beyond the initial goals of the
DIAZOB project, a similar model offers interesting research perspectives for future studies.

A structured psychiatric interview using DSM-IV criteria is considered the gold standard for diagnosing clinical depression [56]. While self-report questionnaires were originally developed to quantify the severity of depression, they are often adopted as time-efficient case-finding instruments in large samples [57]. However, depression is not the only common emotional problem in diabetes patients [58,59]. Depression questionnaires may detect some [56], but certainly not all [58] components of distress. Given the tendency of psychosocial factors to cluster together within individuals [60,61], the simultaneous assessment of multiple distress types seems justified to obtain a more precise risk stratification [60]. Other studies have emphasized the importance of examining both episodic emotional states and more chronic psychosocial factors [60,62]. By extending the focus of our research from a cross-sectional assessment of depressive symptoms to repeated measurements of not only depression, but also Type D personality, we intend to take a step in this direction.

Several other study limitations need to be mentioned. First, while laboratory determinations and physical examinations are part of regular care protocols and therefore did not impose an extra burden on the participating patients, we cannot avoid that for some patients these tests were scheduled several months before or after the official measurement occasion in question. In these cases, we used the test results that were the closest in time to the rest of the data. Secondly, although the prescription of antihyperglycemic and cardiovascular agents was documented relatively well, information on the concurrent use of psychotropic medication is lacking. Earlier studies have suggested that different classes of antidepressant drugs may exert a clinically relevant positive or negative effect on glucose-insulin homeostasis [63]. Requesting pharmacy information from large databases of pharmacy dispensing records [64] might improve the accuracy of medication registration. Finally, although we aim to elucidate the mechanisms responsible for the adverse effect of emotional distress on vascular outcomes, no information was available on several interesting candidate mechanisms, including dysfunctional activity of the hypothalamic-pituitary-adrenal axis, neurotransmitter function or inflammatory processes [31-33].

General practice settings offer relatively favorable conditions for conducting longitudinal research, as the Dutch health care system is characterized by a high level of care continuity between patients and family physicians [65]. In enhancing the quality of longitudinal data collection, it is essential to ensure the provision of solid research facilities, standardization of data between 
practices and over time, and integration of scientific and patient care data collection in a clinician-friendly manner [65]. Planning and conducting longer term epidemiologic studies considerably challenges the motivation and benevolence of participating health care providers. Apart from central coordination of the DIAZOB research infrastructure, PoZoB also contributes to a clinical translation of scientific findings by organising feedback meetings and training programmes, thus enabling an ongoing research commitment of general practitioners and their staff [65]. Keeping an eye on the needs and developments in primary care daily practice, the collaboration between PoZoB and CoRPS, Tilburg University, will provide an excellent framework to explore the wealth of information already available and at the same time ensure a continuing qualitative and innovative development of primary care diabetes research.

\section{Acknowledgements}

This study was supported by a ZonMW grant (call for diabetes health care groups, application number 5881) from the Netherlands Organisation for Health Research and Development to Victor Pop, and by Vici grant \# 45304.004 from the Netherlands Organisation for Scientific Research (The Hague, The Netherlands) to Johan Denollet.

\section{Authors' contributions}

All authors have contributed to the design and content of this study; all authors have read and approved the final manuscript.

\section{Competing interests}

The authors declare that they have no competing interests.

Received: 30 May 2010 Accepted: 1 July 2010 Published: 1 July 2010

\section{References}

1. Wild S, Roglic G, Green A, Sicree R, King H: Global prevalence of diabetes: estimates for the year 2000 and projections for 2030. Diabetes Care 2004, 27:1047-1053.

2. Marshall SM, Flyvbjerg A: Prevention and early detection of vascular complications of diabetes. BMJ 2006, 333:475-480.

3. Zimmet P: Preventing diabetic complications: a primary care perspective. Diabetes Res Clin Pract 2009, 84:107-116.

4. Williams R, Van Gaal L, Lucioni C: Assessing the impact of complications on the costs of Type II diabetes. Diabetologia 2002, 45:S13-17.

5. Quality of life in type 2 diabetic patients is affected by complications but not by intensive policies to improve blood glucose or blood pressure control (UKPDS 37). U.K. Prospective Diabetes Study Group. Diabetes Care 1999, 22:1125-1136.

6. Ali S, Stone MA, Peters JL, Davies MJ, Khunti K: The prevalence of comorbid depression in adults with Type 2 diabetes: a systematic review and meta-analysis. Diabet Med 2006, 23:1165-1173.

7. Peyrot M, Rubin RR: Persistence of depressive symptoms in diabetic adults. Diabetes Care 1999, 22:448-452.

8. Mezuk B, Eaton WW, Albrecht S, Golden SH: Depression and type 2 diabetes over the lifespan: a meta-analysis. Diabetes Care 2008, 31:2383-2390

9. Nouwen A, Lloyd CE, Pouwer F: Depression and type 2 diabetes over the lifespan: a meta-analysis. Response to Mezuk et al. Diabetes Care 2009 32:e56, author reply e57.

10. Knol MJ, Twisk JW, Beekman AT, Heine RJ, Snoek FJ, Pouwer F: Depression as a risk factor for the onset of type 2 diabetes mellitus. A metaanalysis. Diabetologia 2006, 49:837-845.

11. Beekman AT, Geerlings SW, Deeg DJ, Smit JH, Schoevers RS, de Beurs E, Braam AW, Penninx BW, van Tilburg W: The natural history of late-life depression: a 6-year prospective study in the community. Arch Gen Psychiatry 2002, 59:605-611.

12. Vuorilehto MS, Melartin TK, Isometsä ET: Course and outcome of depressive disorders in primary care: a prospective 18-month study. Psychol Med 2009, 39:1697-1707.

13. Lustman PJ, Griffith LS, Freedland KE, Clouse RE: The course of major depression in diabetes. Gen Hosp Psychiatry 1997, 19:138-143.

14. Pibernik-Okanovic M, Begic D, Peros K, Szabo S, Metelko Z: Psychosocial factors contributing to persistent depressive symptoms in type 2 diabetic patients: a Croatian survey from the European Depression in Diabetes Research Consortium. J Diabetes Complications 2008, 22:246-253.

15. Hermanns N, Kulzer B, Reinecker H, Kubiak T, Haak T: Course of depression in Type 2 diabetes. 40th EASD Meeting. Munich, Germany 2004.

16. Lustman PJ, Anderson RJ, Freedland KE, de Groot M, Carney RM, Clouse RE: Depression and poor glycemic control: a meta-analytic review of the literature. Diabetes Care 2000, 23:934-942.

17. Katon WJ, Lin EH, Russo J, Von Korff M, Ciechanowski P, Simon G, Ludman E, Bush T, Young B: Cardiac risk factors in patients with diabetes mellitus and major depression. J Gen Intern Med 2004, 19:1192-1199.

18. de Groot M, Anderson R, Freedland KE, Clouse RE, Lustman PJ: Association of depression and diabetes complications: a meta-analysis. Psychosom Med 2001, 63:619-630.

19. Black SA, Markides KS, Ray LA: Depression predicts increased incidence of adverse health outcomes in older Mexican Americans with type 2 diabetes. Diabetes Care 2003, 26:2822-2828.

20. Egede LE, Nietert PJ, Zheng D: Depression and all-cause and coronary heart disease mortality among adults with and without diabetes. Diabetes Care 2005, 28:1339-1345.

21. Katon WJ, Rutter C, Simon G, Lin EH, Ludman E, Ciechanowski P, Kinder L, Young B, Von Korff M: The association of comorbid depression with mortality in patients with type 2 diabetes. Diabetes Care 2005, 28:2668-2672

22. Zhang X, Norris SL, Gregg EW, Cheng YJ, Beckles G, Kahn HS: Depressive symptoms and mortality among persons with and without diabetes. Am J Epidemiol 2005, 161:652-660.

23. Van der Kooy $K$, van Hout $H$, Marwijk H, Marten $H$, Stehouwer $C$, Beekman A: Depression and the risk for cardiovascular diseases: systematic review and meta analysis. Int J Geriatr Psychiatry 2007, 22:613-626.

24. van Melle JP, de Jonge P, Spijkerman TA, Tijssen JG, Ormel J, van Veldhuisen DJ, van den Brink RH, van den Berg MP: Prognostic association of depression following myocardial infarction with mortality and cardiovascular events: a meta-analysis. Psychosom Med 2004, 66:814-822.

25. Clouse RE, Lustman PJ, Freedland KE, Griffith LS, McGill JB, Carney RM: Depression and coronary heart disease in women with diabetes. Psychosom Med 2003, 65:376-383.

26. Bruce DG, Davis WA, Starkstein SE, Davis TM: A prospective study of depression and mortality in patients with type 2 diabetes: the Fremantle Diabetes Study. Diabetologia 2005, 48:2532-2539.

27. Lin EH, Rutter CM, Katon W, Heckbert SR, Ciechanowski P, Oliver MM, Ludman EJ, Young BA, Williams LH, McCulloch DK, Von Korff M: Depression and advanced complications of diabetes: a prospective cohort study. Diabetes Care 2010, 33:264-269.

28. Denollet J: DS14: standard assessment of negative affectivity, social inhibition, and Type D personality. Psychosom Med 2005, 67:89-97.

29. Pedersen SS, Denollet J: Is Type D personality here to stay? Emerging evidence across cardiovascular disease patient groups. Curr Cardiol Rev 2006, 2:205-213

30. Pedersen SS, Denollet J: Type D personality, cardiac events, and impaired quality of life: a review. Eur J Cardiovasc Prev Rehabil 2003, 10:241-248.

31. Kupper N, Denollet J: Type D personality as a prognostic factor in heart disease: assessment and mediating mechanisms. J Pers Assess 2007, 89:265-276.

32. Lett HS, Blumenthal JA, Babyak MA, Sherwood A, Strauman T, Robins C, Newman MF: Depression as a risk factor for coronary artery disease: evidence, mechanisms, and treatment. Psychosom Med 2004, 66:305-315.

33. Whooley MA, de Jonge $P$, Vittinghoff $E$, Otte $C$, Moos R, Carney RM, Ali S, Dowray S, Na B, Feldman MD, Schiller NB, Browner WS: Depressive symptoms, health behaviors, and risk of cardiovascular events in patients with coronary heart disease. JAMA 2008, 300:2379-2388. 
34. Koopmans B, Pouwer F, de Bie RA, van Rooij ES, Leusink GL, Pop VJ: Depressive symptoms are associated with physical inactivity in patients with type 2 diabetes. The DIAZOB Primary Care Diabetes study. Fam Pract 2009, 26:171-173

35. Koopmans B, Pouwer F, de Bie RA, Leusink GL, Denollet JK, Pop VJ: Associations between vascular co-morbidities and depression in insulinnaive diabetes patients: the DIAZOB Primary Care Diabetes study. Diabetologia 2009, 52:2056-2063.

36. Rutten GEHM, De Grauw WJC, Nijpels G, Goudswaard AN, Uitewaal PJM, Van der Does FEE, Heine RJ, Van Ballegooie E, Verduijn MM, Bouma M: NHG-Standaard Diabetes mellitus type 2: Tweede herziening. Huisarts Wet 2006, 49:137-152.

37. Standards of medical care in diabetes-2008. Diabetes Care 2008, 31(Suppl 1):12-54

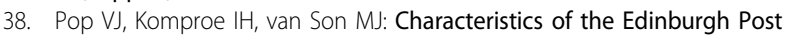
Natal Depression Scale in The Netherlands. J Affect Disord 1992, 26:105-110.

39. Cox JL, Holden JM, Sagovsky R: Detection of postnatal depression Development of the 10-item Edinburgh Postnatal Depression Scale. $\mathrm{Br} J$ Psychiatry 1987, 150:782-786.

40. Cox JL, Chapman G, Murray D, Jones P: Validation of the Edinburgh Postnatal Depression Scale (EPDS) in non-postnatal women. J Affect Disord 1996, 39:185-189.

41. Becht MC, Van Erp CF, Teeuwisse TM, Van Heck GL, Van Son MJ, Pop VJ: Measuring depression in women around menopausal age: towards a validation of the Edinburgh Depression Scale. J Affect Disord 2001 63:209-213.

42. Matthey S, Barnett B, Kavanagh DJ, Howie P: Validation of the Edinburgh Postnatal Depression Scale for men, and comparison of item endorsement with their partners. J Affect Disord 2001, 64:175-184.

43. Nyklíček I, Scherders MJ, Pop VJ: Multiple assessments of depressive symptoms as an index of depression in population-based samples. Psychiatry Res 2004, 128:111-116.

44. Matthey S, Henshaw C, Elliott S, Barnett B: Variability in use of cut-off scores and formats on the Edinburgh Postnatal Depression Scale: implications for clinical and research practice. Arch Womens Ment Health 2006, 9:309-315

45. Martens EJ, Kupper N, Pedersen SS, Aquarius AE, Denollet J: Type D personality is a stable taxonomy in post-MI patients over an 18-month period. J Psychosom Res 2007, 63:545-550.

46. O'Hara MW: Social support, life events, and depression during pregnancy and the puerperium. Arch Gen Psychiatry 1986, 43:569-573.

47. Declaration of Helsinki. BMJ 1996, 313:1448-1449.

48. Mackinnon DP, Fairchild AJ, Fritz MS: Mediation Analysis. Annu Rev Psychol 2007, 58:593-614.

49. Hintze J: PASS 2008 Kaysville, Utah: NCSS, LLC 2008

50. Schiffer AA, Denollet J, Widdershoven JW, Hendriks EH, Smith OR: Failure to consult for symptoms of heart failure in patients with a Type D personality. Heart 2007, 93:814-818.

51. Khunti K, Ganguli S: Who looks after people with diabetes: primary or secondary care? J R Soc Med 2000, 93:183-186.

52. Poortvliet MC, Schrijvers CTM, Baan CA: Diabetes in Nederland: Omvang, risicofactoren en gevolgen, nu en in de toekomst Bilthoven: Rijksinstituut voor Volksgezondheid en Milieu 2007.

53. Ubink-Veltmaat $L J$, Bilo HJ, Groenier KH, Rischen RO, Meyboom-de Jong B: Shared care with task delegation to nurses for type 2 diabetes: prospective observational study. Neth J Med 2005, 63:103-110.

54. Vrijhoef HJ, Diederiks JP, Spreeuwenberg C, Wolffenbuttel BH, van Wilderen LJ: The nurse specialist as main care-provider for patients with type 2 diabetes in a primary care setting: effects on patient outcomes. Int J Nurs Stud 2002, 39:441-451.

55. Pouwer F, Beekman AT, Lubach C, Snoek FJ: Nurses' recognition and registration of depression, anxiety and diabetes-specific emotional problems in outpatients with diabetes mellitus. Patient Educ Couns 2006, 60:235-240.

56. Fisher L, Skaff MM, Mullan JT, Arean P, Mohr D, Masharani U, Glasgow R, Laurencin G: Clinical depression versus distress among patients with type 2 diabetes: not just a question of semantics. Diabetes Care 2007, 30:542-548.

57. Sheeran T, Zimmerman M: Case identification of depression with selfreport questionnaires. Psychiatry Res 2002, 109:51-59.
58. Hermanns N, Kulzer B, Krichbaum M, Kubiak T, Haak T: How to screen for depression and emotional problems in patients with diabetes: comparison of screening characteristics of depression questionnaires, measurement of diabetes-specific emotional problems and standard clinical assessment. Diabetologia 2006, 49:469-477.

59. Pouwer F: Should we screen for emotional distress in type 2 diabetes mellitus? Nat Rev Endocrinol 2009, 5:665-671.

60. Pelle AJ, Denollet J, Zwisler AD, Pedersen SS: Overlap and distinctiveness of psychological risk factors in patients with ischemic heart disease and chronic heart failure: are we there yet? J Affect Disord 2009, 113:150-156

61. Rozanski A, Blumenthal JA, Kaplan J: Impact of psychological factors on the pathogenesis of cardiovascular disease and implications for therapy. Circulation 1999, 99:2192-2217.

62. Kop WJ: Acute and chronic psychological risk factors for coronary syndromes: moderating effects of coronary artery disease severity. $J$ Psychosom Res 1997, 43:167-181.

63. Mclntyre RS, Soczynska JK, Konarski JZ, Kennedy SH: The effect of antidepressants on glucose homeostasis and insulin sensitivity: synthesis and mechanisms. Expert Opin Drug Saf 2006, 5:157-168.

64. Knol MJ, Derijks HJ, Geerlings MI, Heerdink ER, Souverein PC, Gorter KJ Grobbee DE, Egberts AC: Influence of antidepressants on glycaemic control in patients with diabetes mellitus. Pharmacoepidemiol Drug Saf 2008, 17:577-586.

65. van Weel C: Longitudinal research and data collection in primary care. Ann Fam Med 2005, 3(Suppl 1):46-51.

Pre-publication history

The pre-publication history for this paper can be accessed here: http://www.biomedcentral.com/1471-2458/10/388/prepub

doi:10.1186/1471-2458-10-388

Cite this article as: Nefs et al:: Psychological risk factors of micro- and macrovascular outcomes in primary care patients with type 2 diabetes: rationale and design of the DiaDDZoB Study. BMC Public Health 2010 10:388.

\section{Submit your next manuscript to BioMed Central and take full advantage of:}

- Convenient online submission

- Thorough peer review

- No space constraints or color figure charges

- Immediate publication on acceptance

- Inclusion in PubMed, CAS, Scopus and Google Scholar

- Research which is freely available for redistribution

Submit your manuscript at www.biomedcentral.com/submit
Biomed Central 